\title{
Pedro Laín Entralgo, una visión filosófica del cuerpo: Yo soy mi cuerpo*
}

\author{
Pedro Lain Entralgo, a philosophical visión of the body: I am my body \\ JONNY AleXANDER GARCía EcheVERri** \\ Universidad Católica de Oriente, agarcia@uco.edu.co \\ Conrado de Jesús Giraldo ZuluagA*** \\ Universidad Pontificia Bolivariana, conrado.giraldo@upb.edu.co
}

Nicolás DuQue NaranJo****

Universidad Pontificia Bolivariana, nico.duque.n@gmail.com

Recibido el 24 de mayo de 2020, APRobado el 30 dE AGOSTo de 2020

\begin{abstract}
RESUMEN
Decir "yo soy mi cuerpo" es ampliar la apuesta filosófica y antropológica que hace Laín, en la cual se refleja el compromiso del ser humano con su situación vital; es tener conciencia del aquí y el ahora. Se evidencia, dentro de este tratado, la influencia de la propuesta de Ortega y Gasset al decir "Yo soy yo y mi circunstancia, y si no la salvo a ella no me salvo yo" (2004, p. 757), a su vez, nos adentramos en los planteamientos filosóficos de Julián Marías Aguilera desde los cuales se asume al ser humano como un proyecto futurizo que necesita encarnarse en su propia vida, para crear otra realidad que lo salve a través de la historia.
\end{abstract}

\section{Palabras Clave}

Antropología integral, cuerpo, instalación, vida, proyecto.

\begin{abstract}
To say "I am my body" is to broaden Lain's philosophical and anthropological stance, which reflects the human being's commitment to his vital situation; It is to be aware of the here and now. The influence of Ortega y Gasset's proposal is evidenced by saying "I am me and my circumstance, and if I don't save her, I don't save myself" (757), in turn, we go into Julián Marías Aguilera's philosophical approaches from which the human being is assumed as a futuristic project that needs to be embodied in his own life, to create another reality that saves him through history.
\end{abstract}

\section{KeYwords}

Integral anthropology, body, installation, life, project.

\footnotetext{
* Este artículo de reflexión pertenece al proyecto investigativo titulado "antropología integral" del grupo de investigativo "filosofía y teología crítica" de la Universidad Católica Luis Amigó (Medellín).

** Candidato a Doctor en Filosofía, Magíster en Filosofía, Teólogo, Bachiller canónico en Filosofía, Licenciado en Etnoeducación por la Universidad Pontificia Bolivariana. Docente de la Universidad Católica de Oriente (Rionegro, Antioquia, Colombia). Líder del grupo Humanitas de la Facultad de Teología y Humanidades.

(iD) orcid.org/0000-0002-4273-9917 Google Scholar

*** Doctor en Filosofía, Magíster en Gerencia para el desarrollo y Licenciado en Filosofía por la Universidad Pontificia Bolivariana. Miembro del grupo de investigación Epimeleia de la Escuela de Teología, Filosofía y Humanidades de la UPB. Docente investigador titular de la misma universidad (Medellín, Antioquia, Colombia). (D) orcid.org/0000-0003-1885-9158 Google Scholar

****Magíster en Filosofía y Filósofo por la Universidad Pontificia Bolivariana. Miembro del Grupo de Investigación en Trabajo Social (GITS) de la Escuela de Ciencias Sociales de la UPB. Docente del Colegio Fontán (Envigado, Antioquia, Colombia).

(D) orcid.org/0000-0003-3934-1171 Google Scholar
} 


\section{Introducción}

Pasar de la pregunta meramente biológica o fisiológica del cuerpo a la pregunta filosófica, es ampliar los horizontes que sobre el ser humano se han dado en la historia. Cuando la pregunta sobre la realidad del ser humano (como individuo) sale de adentro y se enfrenta a la filosofía, surge un ejercicio puramente filosófico: aquel en el que yo y tú se identifican en su preguntar. La filosofía tiene sentido, como dice Buber (1964) en su obra ¿Qué es el hombre?, cuando: "el hombre va al encuentro consigo mismo, cuando puede descubrir en su propio yo al hombre, y en sus propios problemas a los del hombre. Él va al encuentro de su esencia cuando se asume como problema" (16).

Aunque la realidad de ser humano esté direccionada por las elecciones que hace, su existencia no es toda elección: la vida y la muerte, el lugar donde se nace, el grupo familiar, el tiempo, entre otras categorías más de la vida, no son elegibles. "Por eso cuando queremos estudiar al ser humano no podemos prescindir de su realidad corpórea; la vida del hombre es libertad, capacidad de entender y de amar: pero es también actividad de los órganos de percepción y función digestiva" (Soler Puigoriol 53). La corporeidad es una unidad vitalbiológica y psicológica $\mathrm{o}$, tal vez, como dice Zubiri, una realidad dinámica estructural que, por solidaridad, unifica la estructura física y psicológica, evitando así toda imposición de una estructura sobre el hombre. De esto da razón Laín al afirmar: "Como dice nuestro pueblo, uno está siempre tirando de su cuerpo. La vida se hace, en efecto, tirando del cuerpo a través de la historia y desde la intimidad personal" (Las generaciones 24).

El propósito central de la presente reflexión se direcciona a formular una visión del cuerpo de carácter integral. Para hacerlo, será necesario indagar por la historia del cuerpo en la filosofía. De modo específico, entender cuál fue la concepción de la corporeidad que legó la modernidad a la filosofía contemporánea y resaltar, a partir de ello, el aporte significativo de la fenomenología de Husserl en la actualidad y el modo como, a partir de su obra, se resignifica la concepción filosófica sobre el cuerpo, para poder llegar a la propuesta antropológica lainiana en la que se refleja el cuerpo como una dimensión constitutiva de la vida humana. Para Laín, indudablemente el cuerpo es objetividad y subjetividad, interioridad y exterioridad, historia y autobiografía, y por ello habrá que expresar, no mi cuerpo y yo, sino, "mi cuerpo soy yo" (Laín, Ser 351). 


\section{La deuda con el cuerpo en la historia de la Filosofía}

Aunque en la filosofía la pregunta por el ser humano ha tenido particular interés, su realidad corpórea ha sido poco profundizada. La empresa de ser humano ha sido entendida de múltiples maneras, pero poco considerada desde su cuerpo. Es pertinente resaltar el hecho de que en la filosofía haya existido, desde su inicio, una preocupación o tendencia a exaltar en la condición de la persona una sola de sus dimensiones, un elemento diferenciador que le imprime un sello de originalidad: logos, pensamiento, alma o psiquis. También hay que sentir de la filosofía el hecho de que el cuerpo no haya sido asumido integralmente. Para nuestro tiempo es ya conocida la gran herida que abrió ante la historia la concepción dualista del ser humano; esta visión trajo consigo violencia, rechazo y dio como resultado, entre otros asuntos, la proclamación de la muerte de Dios.

Fue necesario reconocer que el elemento que diferenciaba al ser humano del resto del cosmos, su espíritu (Scheler) o su alma (cristianismo), no fue la mejor explicación ni el mejor paradigma que la filosofía haya tenido. Ante este hecho, los pensadores contemporáneos se dieron a la tarea de volver a comenzar, la filosofía se replanteó las preguntas y anduvo por otros caminos para encontrar nuevas respuestas. Hubo incluso algunos autores que recorrieron los mismos caminos de la tradición, enfatizando su mirada en aspectos antes no resaltados o tenidos en cuenta. Todo este esfuerzo con la finalidad de construir de mejor manera la empresa de ser humano.

Con todo, se debe reconocer que la visión dualista del ser humano tuvo repercusiones negativas sobre el cuerpo. Algunos acentuaron la condena inmediata del cuerpo, símbolo de materialidad, pasiones y corrupción; otros sobresaltaron demasiado su visión material, llegando a afirmar que el ser humano es un compuesto biológico, no algo más. Conclusión que ha comenzado a tener mucha importancia en nuestros días y que abre una profunda herida en el cuerpo, pues éste se ha convertido en objeto de manipulación biotecnológica.

En la modernidad se esperaba una superación de los viejos modelos, entrados a ella los pensadores iban a dar una mejor explicación del mundo, del ser humano y de la realidad, pero ciertamente en esta época todo fue una verdad a medias; la razón no fue el concepto unificador de las ciencias y mucho menos la explicación más convincente para 
las dudas del ser humano. Se intentó convertir a la filosofía en una ciencia objetiva que diera razón última del sentido de las cosas, pero realmente lo que se hizo fue distanciar, a pasos agigantados, la relación entre los distintos saberes. Las ciencias naturales o biológicas surgieron a partir de este hecho fortalecidas, la medicina es un ejemplo de ello. Al respecto dice el médico Jaime Escobar:

La revolución científica que comienza en el siglo XVII, sólo afecta a la medicina a mediados del siglo XIX, cuando se inicia la medicina auténticamente moderna. Las mismas leyes físicas y químicas debían aplicarse a la interpretación de los fenómenos vitales en la salud y en la enfermedad, pasando, así, a ser sólo ciencia de la naturaleza y suspendiéndose de sus estudios la filosofía: el enfermo se convierte en objeto medible en sus manifestaciones y el médico se interesa menos en su personalidad y más en su formación tecno-científica (46).

El estudio del ser humano se materializa; es éste el denominado dualismo psicofísico el cual nos hace cometer el error de estudiar al hombre como una cosa más entre las cosas; se incurre en la naturalización de la conciencia o cosificación del alma (Escobar 57). Esta situación será la que denunciará Husserl (1984) en su obra La crisis de las Ciencias como una experiencia de la radical crisis vital de la humanidad europea: "la exclusividad con la que, en la segunda mitad del siglo XX, toda la cosmovisión del hombre moderno se dejó determinar por las ciencias positivas y se dejó deslumbrar por la prosperity debida a ellas, significó un alejamiento indiferente de los problemas que son decisivos para un auténtico humanismo" (9).

El racionalismo, el idealismo y el positivismo dela modernidad se vinieron al piso; la contemporaneidad dio sus primeros pasos con un rechazo absoluto a estas corrientes del pensamiento filosófico, las que no hicieron más que acentuar el dualismo antropológico creado desde la antigüedad. El primer pensador que enfatizó su descontento con los dualismos reduccionistas de la modernidad fue Husserl. Dando una interpretación a esta crítica, Miguel Ángel Villamil comenta: "en su conjunto, la fenomenología se opone a la visión dualista del hombre y afirma, en un sentido totalmente diferente a los positivistas, que el hombre es un ser corporal, una conciencia encarnada; que el hombre no piensa desde el cuerpo, ni con el cuerpo, ni a través del cuerpo; el hombre piensa como cuerpo, piensa corporalmente" (19-20). 
De allí que se entienda que una de las consecuencias más graves que trajo consigo el dualismo moderno fue "la concepción del cuerpo como pura extensión" (Villamil 26). Con Descartes, la pregunta por el ser humano estará viciada a un nuevo dualismo: la realidad propia del ser humano es ser espíritu, cuerpo y alma son dos realidades opuestas entre sí. Para Descartes, el ser humano puede alejarse del mundo exterior y, aún más, puede incluso alejarse de su propio cuerpo, ¿es esto posible? Según Laín, Descartes no se detuvo a realizar un análisis de semejante afirmación, a partir de él se entenderá la realidad del alma/cuerpo de la siguiente manera: "En cuanto espíritu, el alma es el sujeto activo de la actividad psíquica del ser humano - sentir, pensar, decidir la ejecución de actos libres, etc. - y de la relación entre el hombre y Dios. Exento de él, ningún ser viviente es capaz ni siquiera de sentir" (Idea 69-70).

El cuerpo, como pura extensión, será comprendido como una banal ilusión o, en el caso de la medicina, como el material adecuado sobre el cual realizar sus experimentos. Increíblemente la modernidad, que juzgó el ideal ascético dado por la religión durante el Medioevo, no se alejó, de manera definitiva, de este error, al contrario, continuó desacreditando la visión del cuerpo. No se logró una concepción diferencial entre lo expuesto por la concepción tradicional y la emergente; la antropología del cuerpo continuó anclada a los extremos, entre dualismo y materialismo, continuaron sin unificarse los planteamientos. Por ello, aunque haya muchas cosas más que decir en contra de las posturas reduccionistas, monistas y dualistas sobre el ser humano, este escrito no tendría razón de ser si no surgiere a partir de la crítica, una vía alternativa que se muestre integradora de la realidad del ser humano y que tome distancia de las posiciones extremas a las que se somete la antropología del cuerpo.

\section{Resignificar el cuerpo, los nuevos horizontes de la filosofía}

La contemporaneidad será la época oportuna para dar un giro en la manera de asumir nuestra realidad. Hoy debe interrogarse: ¿qué es solamente orgánico en el ser humano? ¿qué es sólo psíquico? y a ello tendrá que responder. El primer pensador que dio al cuerpo un lugar de importancia fue Husserl; con la fenomenología iniciará una visión filosófica sobre el cuerpo humano. Laín así lo expresa: "El cuerpo se le presenta a Husserl como mediador necesario de la ejecución de la propia existencia y de la instalación espacio-temporal en el cosmos, 
más también como realidad material que se siente a sí misma" (Idea 116). Se abre así un espacio de resignificación del cuerpo en el que habrá que sumergirse con el fin de ofrecer una comprensión abierta de la realidad humana en la que el cuerpo sea expresión de la realidad interna y externa del ser humano.

Hablar del cuerpo es una tarea que requiere de esfuerzo y dedicación. Son numerosas las miradas y perspectivas que se han desplegado sobre éste, con una intención: resignificarlo. De Husserl a Laín, hay una variedad de autores que han dedicado sus esfuerzos a la reconstrucción del ser humano y de su cuerpo. Sin embargo, en el castellano, escasean, tanto las propuestas antropológicas como los conceptos adecuados, para formular una comprensión de la realidad corporal del ser humano que permita liberar al cuerpo de todo monismo o dualismo. Por esta razón debe cuestionarse ¿qué concepto es claro e íntegro a la hora de abordar el tema del cuerpo en la filosofía? y, así mismo, ¿qué autor o autores han formulado, en el castellano, una concepción integral del cuerpo humano?

Cuando se escribe la palabra cuerpo se corre el riesgo de quedar atrapado en el ámbito del mero materialismo o el cientismo (objetivismosmaterialismos). Igual pasa cuando en la filosofía se sostienen tesis como las de la conciencia pura, el yo puro, espíritu puro o incluso, el concepto de alma, entendida como una subestructura del ser humano que está por encima del cuerpo (subjetivismos-espiritualismos). ¿Cuál es, entonces, el concepto mejor elaborado que ha permitido a la contemporaneidad construir una nueva interpretación sobre el ser humano y su cuerpo, libre de los monismos y dualismos reduccionistas que habitan en la actualidad?

Pensadores como Ortega y Gasset, Merleau-Ponty, Sartre, Heidegger, Zubiri, Laín, han posibilitado una visión integral del ser humano en la que se encuentran lo objetivo y lo subjetivo del tratado sobre el cuerpo. Sea espíritu encarnado, como dijo Merleau-Ponty, o corporeidad anímica, como dijo Zubiri (Villamil 42-43), se procura una nueva concepción que reúna esas dos realidades o sustancias que han sido opuestas a través de la historia.

El cuerpo, tal y como es comprendido hoy, no es sólo un residuo, el resultado del azar y la necesidad, la evolución de la materia en el cosmos; el ser humano no es, por suerte, un animal que logró avanzar gracias al proceso de bipedestación o el desarrollo del lóbulo frontal; hasta nuestra 
estructura corporal dice cosas diferentes a las de un animal. Por estas razones el concepto de cuerpo se ha convertido en una tarea que todo investigador no puede dejar pasar por alto. Husserl en Ideas relativas a una fenomenología pura y una filosofía fenomenológica dirá:

El cuerpo (Leib) se constituye originariamente de doble
modo: por una parte es cosa física, materia, y así tiene su
extensión, en la cual entran sus propiedades reales, color,
lisura, dureza, calor y las restantes propiedades materiales,
y por otra parte yo encuentro sobre él y siento sobre él y en
él: calor en el dorso de la mano, frío en los pies, sensaciones
de contacto en las puntas de los dedos. Extendidos sobre
la superficie de amplias zonas del cuerpo siento la presión
y el desplazamiento del traje (145-146).

Lo expresado por Husserl da lugar a una nueva comprensión antropológica del cuerpo en la que éste es pensado como cosa (extensión material) y como experiencia (subjetividad). A partir de este momento, la filosofía se dará a la tarea de precisar por medio de nuevos contextos, en este caso dentro del idioma alemán, un concepto que permita comprender al ser humano de forma integral. El profesor Luis Aguilar nos dice al respecto: "La lengua alemana dispone de dos términos para designar la misma realidad. Körper, el cuerpo como realidad material, que se constata mediante los sentidos. Leib, que es el cuerpo como organicidad, como objeto de una experiencia compleja y unitaria, experiencia que remite a un sujeto. Leib es la condición corpórea, la corporeidad" (154). Para pensadores como Armando Rigobello (2000), el concepto del cuerpo como Leib es desconocido, por lo que se hace necesario que en nuestros días el investigador se dé a la tarea de explorar el concepto, nos dice: "El Körper plantea los problemas clásicos, pero en el plano de la corporeidad nos adentramos en un mundo poco explorado por la reflexión crítica. Un mundo intensamente vivido y muy abundante en signos que se prestan a diversas interpretaciones" (57).

En el contexto latinoamericano, los conceptos del cuerpo como Körper o Leib ya han tomado fuerza. Al hablar del cuerpo se hace referencia a lo objetivo-orgánico y cuando hablamos de "corporeidad" se hace mención de lo subjetivo existencial en el ser humano. Se hace posible, de este modo, una nueva visión sobre el cuerpo en la que el ser 
humano se vea humanizado, su condición se transforme en una realidad personal para abandonar su total cosificación, su vida se expresa en la convivencia, en otras palabras, se habilita una nueva circunstancia vital para el cuerpo, aquella en la que éste es comprendido como cosa y sujeto, como física y psíquica, sin que haya que dar preeminencia a una sobre la otra. El ideal de totalidad o integridad del ser humano ha iniciado su camino y va fortaleciéndose en nuestra historia, mencionar el cuerpo ya no debe ser signo de contrariedad o materialidad. "La corporalidad se refiere al cuerpo humano en la medida en que implica espíritu, de lo contrario ya no sería cuerpo humano" (Aguilar 155).

\section{La importancia del concepto de corporeidad en la filosofía contemporánea}

El término corporeidad no es para nada desconocido, no es un neologismo que ha aparecido hace algunos años o una palabra que tenga un uso restringido dentro de alguna disciplina o saber. Es usado cotidianamente con la intención de señalar algo originariamente corporal. El concepto ha sido también usado por las ciencias positivas como expresa Miguel Villamil:

Lo que la ciencia positiva de anatomistas y fisiólogos enseña acerca de la corporeidad del hombre no se refiere al cuerpo, en cuanto sujeto, sino al cuerpo en cuanto objeto; aquello sobre lo cual hablan estas ciencias no es "mi" cuerpo, sólo lo hago "mío" en el momento en que establezco comunicación con él a partir de mis experiencias corporales (36).

El concepto de corporeidad, si bien no es nuevo, despega vuelo en la actualidad, gracias a la nueva interpretación con la que los pensadores contemporáneos han utilizado el término. Hablar de corporeidad es reformular la pregunta que hace referencia a la realidad del ser humano; es pasar de un qué es a un cómo es, dando lugar a la vivencia subjetiva e interpersonal en la que el ser humano se reconoce así mismo. En otras palabras, hablar de corporeidad es hablar también del sujeto, sin reducirlo a su mera intimidad. El cuerpo es el lugar que habita de forma natural el ser humano, el lugar desde el cual se vivencia como realidad, se relaciona con los otros y descubre lo que es el mundo. 
Es la contemporaneidad el espacio propicio para habilitar la experiencia del cuerpo. Sólo hasta ahora, la corporeidad se hace morada del sujeto, como dirá Merleau-Ponty (1975): “[...] el cuerpo propio es una permanencia del lado de mí, nunca está verdaderamente delante de mí (como objeto), no puedo desplegarlo bajo mi mirada. El cuerpo propio se queda al margen de todas mis percepciones, está conmigo" (108). Estar "en mi cuerpo", "ser en mi cuerpo" es el fundamento de la experiencia vital de todo ser humano y, este sentido verdaderamente trascendente, es por el que vale la pena esforzarse en una investigación filosófica con el fin de encaminar al ser humano hacia una pasión humana y humanizadora: pensarnos. Dice Villamil: "El mundo no es una realidad cruda separada absolutamente del sujeto, sino un ser que se muestra, un fenómeno, un significado para el hombre. El hombre no es un Espíritu, sino un ser que está incorporado en sentidos definidos, los cuales implican una actitud definida y delimitan un mundo para mí" (37).

El reconocimiento del material por el cual está compuesto el cuerpo no puede arrebatar el sueño. Es necesario enfocar, desde un lugar diferente, la concepción que se tiene sobre el cuerpo, ya que el ser humano es "esencialmente mundano y el mundo es esencialmente humano" (Lyupen 33) o, como dirá Sartre en su obra El ser y la nada: ensayo de ontología fenomenológica: "Un mundo sin el hombre no es un mundo, y un hombre sin el mundo no es un hombre" (334).

Hablar de corporeidad, dentro de la filosofía, recoge un sin número de elementos que totalizan o integran la visión que se tiene del ser humano en la actualidad. El cuerpo se hace tema para la medicina, la fenomenología, la hermenéutica: todos los saberes se encaminan a una reivindicación del cuerpo. Asistimos a la apertura del sujeto al objeto, dirá Villamil:

Dicha concepción entraña ya la corporeidad como nota esencial, sin la cual sería imposible la comunicación del sujeto con los demás seres del mundo (cosas, animales, otros, Dios). De esta manera, nos liberamos de la esclavitud del objeto y, a la vez, de las posibles arbitrariedades del sujeto; ambas tesis sustentadas por los sistemas filosóficos clásicos: el empirismo y el racionalismo (55). 
Es por ello que cuando Laín da a la construcción del ser humano el título de empresa, no está distante de esta realidad, el ser humano es hacedor y hechura de su propio ser (Villamil 55); "el hombre es un ser que se pregunta, se interpreta a sí mismo porque sabe que necesita una imagen rectora que le ayude a construirse y a constituirse" (Landmann 9). Según Luis Aguilar:

En mi naturaleza corpórea el espíritu humano no descubre sólo un objeto suyo: se descubre a sí mismo, ya que tal naturaleza es la de un sujeto espiritual (con capacidad de conciencia, libertad, compromiso y entrega); mi mismo espíritu forma parte de él. Por eso tiene la misma dignidad. Lo que impide al sujeto disponer de su propio cuerpo como un objeto es su unidad sustancial (157).

Descubrir el concepto de corporeidad es dar al cuerpo un sentido totalizante, es afirmar al cuerpo como espíritu encarnado o unidad corpóreo-espiritual. No hay que volver mil veces sobre la palabra para captar lo que en la contemporaneidad se busca decir, basta con afirmar que decir cuerpo es aludir a la totalidad.

\section{Mi cuerpo soy yo, una propuesta lainiana}

Decir el cuerpo resulta desconcertante ¿desde dónde se dice el cuerpo? Como "un objeto indeseable, como una realidad a soportar, como un aspecto a la hora de la verdad, ajeno al ser humano o por el contario como un organismo material o un compuesto biológico" (Villamil 19). Sea desde la hermenéutica, la fenomenología o la antropología (científico-filosófica), la filosofía dice de otro modo el cuerpo: “[...] el hombre es un ser corporal, una conciencia encarnada; que el hombre no piensa desde el cuerpo, ni con el cuerpo, ni a través del cuerpo; $e l$ hombre piensa como cuerpo, piensa corporalmente" (Villamil 20).

El pensamiento, la reflexión, la conciencia no son actos desencarnados, antes bien, tienen lugar en el cuerpo, en éste se conserva una postura ante cada acto. Pensar es un acto que ejecuta el cuerpo y todos lo pueden notar, es a partir de la corporalidad como el ser humano expresa todo su sentir; lo que no dice con sus palabras lo dice a través de su cuerpo. Amar, odiar, desear, como también pensar, intelegir o ser consciente son actos propios que ejecuta el ser humano en su corporalidad. 
Caminar es tan propio en el cuerpo como pensar: "La reflexión y lo irreflexivo son las dos caras del constituir corporal" (Villamil 20). ¿De qué manera podría decirse que el cuerpo va más allá de la palabra, que trasciende o dice lo que las palabras no pueden? Por medio del cuerpo el ser humano demuestra su amor, su alegría; en su mirar, en su donación, en sus múltiples manifestaciones, el ser humano se entrega completamente como cuerpo. Esto mismo dirá Miguel Ángel Villamil:

Tal vez, mediante el análisis, podamos diferenciarlas, pero la existencia propia, mi experiencia vivida, nos ofrece la profunda certeza de la unidad esencial y total del ser humano; la cual no surge al final de una argumentación filosófica o científica, sino que se nos presenta inmediatamente en la cotidianidad, en el día tras día, es una experiencia tan evidente que resulta imposible ponerla radicalmente en duda (32).

Hay que hacer particular énfasis en la manera como el cuerpo habla en la cotidianidad sin necesidad de presiones, en un acto natural da de sí, nos devela lo que piensa, lo que quiere. Aunque andar, reír, comer son actos que nos han puesto en semejanza con los animales, también nos han diferenciado; hasta estos actos nos dicen algo sobre lo que es el ser humano, cada acto exterior del ser humano, por cotidiano que parezca, envuelve una situación interna de su ser.

En la fenomenología expuesta por Husserl encontramos un camino que nos direcciona hacia la comprensión corporal del ser humano, en ella se da un lugar de preferencia para comprenderle como totalidad: el mundo de la vida. Villamil hace referencia a esta situación al afirmar: "Me identifico con mi cuerpo en cuanto existo mi cuerpo, y en esa medida coexisto con el mundo: sin mi cuerpo no sería nada. Mi cuerpo está situado en el mundo aquí y ahora. En cuanto al ahora, soy siempre presencia; en cuanto al aquí, estoy dotado de características físicas: mis brazos son voluminosos, mis piernas son extensas" (32).

El cuerpo percibe, saborea, es un organismo biológico, tiene hábitos, es instintivo, sexuado, expresivo, es lo que me permite ser consciente de que existo, de que estoy aquí en el mundo (Villamil 32). El cuerpo dice muchas cosas. Para Laín serán todas estas cualidades del cuerpo las que permiten decir "mi cuerpo: yo", dirá en Ser y conducta del hombre: 
"No "mi cuerpo y yo", sino "mi cuerpo: yo". No la autoafirmación de uno "yo" para el cual algo unidísimo a él, pero distinto de él, el cuerpo, fuese dócil o rebelde servidor - implícitamente, eso lleva dentro de sí la expresión "mi cuerpo" -, sino la autoafirmación de un cuerpo que tiene como posibilidad decir sí mimo "yo" (351-352).

"Mi cuerpo soy yo" (Laín, Ser 351) es la invitación particular que hace el autor a todo lector de su obra, para que se abra paso desde su cuerpo a la realidad que le rodea. Desde mi aquí y mi ahora (Laín, Ser 362), es decir, desde el ambiente vital de cada persona, el ser humano asciende al entendimiento de lo que es como resultado de un devenir histórico y una situación social (Laín, Ser 379), para concluir que no sólo se es el resultado de un desarrollo embriológico, sino ante todo el resultado de un proceso biográfico (Laín, Ser 388).

"Mi cuerpo viviente", y en él mi cerebro, no se reduce a un organismo con una conciencia que le capacita para decir yo; es la actividad de una estructura dinámica que tiene la posibilidad de dar expresión a su realidad personal diciendo yo. Es mi cuerpo viviente el que piensa, siente y quiere, escribió Unamuno. Pues bien: desde un cuerpo, el mío, que puede decir y a veces dice yo, he tratado de dar razón de mi realidad en el espacio y en el tiempo, de cómo biológica, histórica y biográficamente he llegado a ser el que soy y lo que soy (Laín, Ser 351).

\section{"Yo soy mi cuerpo" una crítica de Laín a Descartes}

La experiencia que brota del pensamiento de Pedro Laín Entralgo de ser yo mi cuerpo (Ser 307) es una crítica directa al centro de la filosofía cartesiana. Según Laín, "Descartes dudó de su propia existencia, y pensó haber salido de su duda apelando a la experiencia inmediata de su propio pensar" (Ser 306). Por eso, este mismo autor, califica su sentencia como un razonamiento secundario y artificioso, a la postre inútil (Ser 307), ya que no ve en la duda cartesiana un interrogante lógico, además afirma:

Para que la sentencia cartesiana alcance validez probatoria habría que dar a la afirmación en que tiene su punto de partida yo pienso una expresión psicológica y gramaticalmente más adecuada al que en realidad es mi experiencia de mí mismo. Porque lo que en realidad yo 
advierto en mí al decir yo pienso es yo estoy pensando, yo estoy realizando el acto temporal y no instantáneo (Ser 307).

Hacer una experiencia personal del cuerpo es la mejor manera de enriquecer la filosofía. De este postulado lainiano surge la posibilidad de confrontación entre la experiencia de cuerpo que vivía Descartes y la de Laín. Es así como los horizontes se amplían. Villamil lo expresa de mejor forma al comentar:

\begin{abstract}
Mi experiencia personal total de identificación y trascendencia corporal se me presenta como materia prima para filosofar. Con base en ella puedo darle sentido $\mathrm{y}$ valor de verdad a mi realidad. De tal manera que mi verdad sea verdad para todos. Mi verdad es válida hasta que otra persona exprese lo in-expresado por mí. En la medida en que confronto la verdad de otras experiencias con mi verdad, enriquezco el horizonte de mi filosofar $y$, por ende, el horizonte de la verdad misma (33).
\end{abstract}

Según Laín, la realidad del cuerpo es lo que posibilita al hombre situarse frente a su existencia, dudar sobre ella resulta algo inútil (Ser 307) ya que "[...] mi conciencia de ser y vivir aquí y ahora es siempre, en una $\mathrm{u}$ otra forma, conciencia de mi cuerpo, experiencia de una actividad de la que el cuerpo es parte esencial" (Ser 308).

El cuerpo, por lo tanto, me brinda certeza de que existo, no se necesita elaborar un profundo razonamiento para validar nuestra existencia. La respuesta a Descartes no es inmediata, desde la identificación del ser humano como tiempo, su situarse en el aquí y ahora, la conciencia de su existir y su instalación en la vida son los rasgos constitutivos del viaje que ahora se emprende.

\title{
Decir el cuerpo en la filosofía
}

La concepción del cuerpo que tiene lugar en el pensamiento lainianio, es el resultado de una profunda reflexión sobre la filosofía de Husserl, Ortega y Gasset, Sartre y Merleau-Ponty. Laín, encuentra una singularidad en lo que cada pensador dice: sus concepciones sobre el ser humano son comparables a la experiencia que cada persona en general tiene de sí. Siendo así: ¿qué puede decir el ser humano 
sobre su cuerpo que sea sólo característico de su individualidad? Al respecto dice Laín:

\begin{abstract}
No es este el caso en las que ahora escribo. En ellas quiero hablar de mi cuerpo no por el hecho de ser cuerpo propio genéricamente humano, sino por ser yo mismo; por tanto, de lo que soy yo y es mi vida, si es cierta la concepción corporalista de la realidad humana que acabo de proponer; de mí mismo, según las certidumbres y las ideas, los deseos y las creencias que me hacen ser lo que soy (Ser 352).
\end{abstract}

Hablar del cuerpo no es sólo un hecho que se corresponde en la filosofía con cualquier cuerpo en general, sino con mi cuerpo propio. "Consignado lo cual, diré lo que yo, mi cuerpo, pienso que soy y creo ser aquí y ahora" (Laín, Ser 353). Decir "mi cuerpo, yo" (Ser 351), debe ser leído como la aceptación de lo que se es como persona humana, la misión y responsabilidad que tiene como ser situado en un lugar, un aquí y un ahora:

Puesto que mi cuerpo es tempóreo, fluye en el tiempo, la percepción de mí mismo me remite inmediatamente a un "ahora", al instante del tiempo cósmico y del tiempo histórico en que estoy ejercitando la actividad de vivir y pensar. Y puesto que de manera tan radical e inexorable son notas de mi existencia personal la conciencia de mi aquí y la conciencia de mi ahora, acaso no sea impertinente comenzar por mi análisis de una y otra la personal autovisión que de su corpórea realidad - de mi personal realidad - pretendo hacer (Laín, Ser 352-353).

El paso del tiempo cósmico al tiempo histórico indica un compromiso: ¿para qué se vive? ¿para qué se piensa? Para decir algo sobre lo que somos y hay a nuestro alrededor: "la ciudad donde resido, el paisaje que la rodea, las mil y unas ciudades y los mil y un paisajes a donde yo podría ir y en que podría estar" (Laín, Ser 354). Hay en el pensamiento de Laín un compromiso con su realidad (aquí y ahora). Por eso, como ser humano, expresa sus ideas y creencias sobre el lugar, el mundo, el espacio que habita. En el cuerpo se continúa la historia del universo o, como dice él mismo: "Mi cuerpo, esta mano que veo, este torso es el aquí casi infinitamente pequeño de un espacio 
estelar casi infinitamente grande. Por grande que sea mi humildad, nunca será proporcionada a lo que para mi admiración y mi espanto me dicen esas cifras" (Laín, Ser 355).

El cuerpo es signo de la pequeñez del ser humano frente al universo; espanto, admiración son las palabras que se emplean para decir lo que como realidad física somos: casi nadie.

\begin{abstract}
Mínimo grano de polvo soy yo, es mi cuerpo, cuando lo miro como parte del universo a que pertenece. Pero en el secreto seno de mi pequeñez, mi admiración y mi espanto soy también, como Pascal, como Kant, como Unamuno, aunque a mi modo, alguien capaz de enfrentarse intelectualmente con la inmensa realidad material que la envuelve y la condiciona (Laín, Ser 355).
\end{abstract}

En Laín, las visiones más imperiosas sobre la realidad del ser humano hablan de su contemplación del universo, desde el ser humano bipedestante que logró mirar fijamente a las estrellas y construir para sí un sistema de creencias que le hacían pensar en la existencia de un ser ordenador, hasta aquella duda sobre su esencia que penetraba tan profundamente, dándole una sazón a su existencia, llevándole a pensar que frente a la inmensidad del cosmos él era algo particular y distinto: el conquistador del mundo, la conciencia de su realidad y existencia.

Decir yo es afirmar que hacemos parte de la historia del universo; decir yo es reconocer la historia humana como parte integral de nuestra existencia. Somos los herederos de la historia, lo que somos no lo debemos sólo a la carga genética de quienes nos han engendrado, lo que somos también se lo debemos a la historia de la humanidad, la historia es toda nuestra. Las acciones, decisiones $\mathrm{u}$ omisiones de nuestros antecesores son una carga que limita o posibilita nuestro sentido y existencia.

Decir "Mi cuerpo, yo" (Laín, Ser 351) es la mejor manera que tiene Laín para precisar lo que es como ser individual: "He hablado hasta aquí de la estructura dinámica del cuerpo humano in genere y de lo que dentro de él hace su órgano más específicamente humano, el cerebro. Ahora debo hablar de mi cuerpo en tanto que mío y en tanto que estructura material capaz de decir de sí misma yo" (Laín, Ser 359). Para Laín el cuerpo es el testimonio vivo del tiempo en el ser humano; 
sentir, pensar, decir el cuerpo, es remitirse a la realidad temporal. Laín mira específicamente el pasado y lo siente suyo, así como Julián Marías Aguilera que cuando analiza el cuerpo, ve el futuro. Según Laín, desde la historia del primer homo hasta la del griego, judío y cristiano son parte de su ser, tienen relación con su singular existencia, le imprimen identidad. Dice: "Calzada su mente con botas no de siete, sino de mil centurias, el hombre actual tiene que verse a sí mismo como titular de una vida en cuya trama de alguna manera perduran modos de vivir iniciados por los homines hábiles que hace treinta mil siglos tallaban piedras para cazar y defenderse" (Laín, Ser 357).

El tiempo es una realidad que le acontece al ser humano, a veces limita su realidad o en otras la enriquece. Este es un concepto que no se logra descifrar objetivamente, que tiene un sin número de sinónimos que manifiestan realidades diferentes. Para ejemplificar, digamos que cuando hablamos de tiempo podemos mencionar movimiento, pero a la vez no podemos afirmar que éste sea movimiento; podemos hablar de años, pero no podemos concluir que sean años. ¿Cuál es la fórmula objetiva del tiempo? ¿De qué manera la ciencia nos puede asegurar que esta categoría es la verdad absoluta del mundo, el ser humano y lo trascendente? Éste es un verdadero enigma. Aun así, ya que el tiempo le adviene al ser humano como pasado, presente o futuro, hay que resaltar que el cuerpo es el testigo fiel de esa manera como el tiempo le afecta. Sobre esto comenta Soler Puigoriol: "El hombre es un ser temporal $y$, aunque no esté totalmente inmerso en esta corriente sucesiva como la roca o el pez, en su vida no puede dejar de apoyar su pie en el presente. Es decir, toda vida humana tendrá forzosamente un pasado, un presente y un futuro" (122).

El cuerpo humano es el conductor del tiempo, es la realidad que no le permite escapar de su situación actual para ir de vuelta, haciéndole consciente de su aquí y ahora y, sobre todo, el cuerpo le ayuda a asumir con responsabilidad el futuro. "La finitud humana, en cambio, es un cabalgar sobre un resbaladizo hoy, siempre con un pie en el ayer y otro en el mañana" (Soler Puigoriol 123). La interpretación de la historia personal del ser humano se manifiesta bajo dos caminos: omitir o elegir, en eso se le va la vida al ser humano, ambas realidades son su responsabilidad, pero, vale aclarar, cuando de conciencia se habla nos duele más lo que dejamos de hacer que lo que no hicimos bien. Lo que aquí señalamos tiene relación con el concepto de finitud que plantea 
Soler Puigoriol: "El hombre es un ser histórico porque es finito" (122). El ser humano vive aterrorizado ante la fugacidad de su vida por lo que se siente responsable de ella, el cuerpo le muestra la "necesidad de la historia" (Soler Puigoriol121). A partir de este enunciado, se entiende el hecho de que el mismo Pedro Soler Puigoriol dedicará unos capítulos de su tratado para resaltar al ser humano como deudor del pasado (120) y proyectado al futuro (179). Todo esto dice el cuerpo, esto hace decir Laín al cuerpo: “Guiado por lo que los libros me enseñan y por lo que veo en mí, cuando históricamente me examino, no menos de diez etapas debo distinguir en el proceso que, dando invisible contenido a mi ahora, ha hecho actual la actividad de mi cuerpo" (Laín, Ser 357).

El cuerpo es el heredero del pasado, el testimonio de la deuda de todo ser humano con su historia. Asumir nuestra historia es uno de los actos menos comunes en la actualidad debido a la burbuja individual que aísla al ser humano contemporáneo de la realidad que padece su momento histórico. No existe un compromiso con la situación vital que sobreviene en su historia. Aun así, Laín no actuó de esta forma, por ello se preguntó: “¿qué sucedió en la vida del género humano para que aquí y ahora yo sea lo que soy? (Ser 358).

No sólo el mirar, también todo acto personal responsabiliza con el otro. Lo que omitimos o elegimos recae sobre los otros. El ser no se aísla de la historia que pasó o que será. Según Soler Puigoriol:

La vida del hombre es constitutivamente problemática. Debe hacer su vida mediante la decisión y resolver su problema fundamental, y éste es precisamente su mismo ser hombre. Tiene en sus manos su existencia y debe resolver el problema de cómo realizarla. Su voluntad libre debe elegir en cada circunstancia entre los muchos caminos que se le ofrecen; de ahí la duda, la perplejidad y la decisión arriesgada y responsable (125).

Asumir la situación histórica es el acontecimiento que le permite al ser humano perfilarse como persona, es frente a la historia, según Soler Puigoriol, como el ser humano repite, imita o crea: "Si bien toda acción humana externa tiene su aspecto histórico, las que en realidad empujan el carro de la Historia y modifican su faz son las acciones creadoras" 
(132). Ser "yo mi cuerpo" (Soler Puigoriol 307) es reconocer la deuda que tengo con el pasado, mi responsabilidad con el aquí y ahora, la conciencia de ser histórico y recurrir a aquellas épocas llenas de éxito y optimismo (Soler Puigoriol 133) que no hacen más que recordarnos la necesidad de crear nuevas situaciones, otras circunstancias; o tal y como dice Laín en Las generaciones en la Historia:

Los hombres -primero unos pocos, los vigías del destino histórico, luego todos ocasi todos-advierten queha entrado en crisis el soporte histórico de su existencia. Mientras no inventen un modo de existir fundamentalmente nuevo, haciendo de corazón cabeza, sus vidas se agitarán sobre un congojoso vacío (113).

A través del cuerpo (mi cuerpo) se comprende el deber. Reconocer su totalidad es tomar posesión de las situaciones que padecemos (desde mi aquí y mi ahora) para comprometernos con el rumbo de nuestros pueblos. Las creencias no son sólo religiosas, las creencias también son políticas, culturales, educativas, económicas. El ser humano, especialmente en Latinoamérica, debe asumir la realidad de su cuerpo para no creer que la realidad que le circunda es irremediable ¿hay que emigrar a otro lugar para vivir de mejor manera? ¿aquí no hay posibilidades para nadie?

Por algo afirmaba Ortega y Gasset (2004): "Yo soy yo y mi circunstancia, y si no la salvo a ella no me salvo yo" (757). No puede existir una concepción integral del hombre si ésta sólo se fundamenta en conceptos y es desencarnada de la realidad. Cuando Laín hace referencia al pronombre posesivo mí, está permitiendo al lector hacer análisis de su responsabilidad con las circunstancias, por eso la realidad vital (mi realidad) de cada ser humano necesita ser redimida. Hablar de redención y salvación de la historia no es signo de una conciencia escrupulosamente religiosa, al contrario, es una manera de expresar la necesidad que tiene nuestra situación circunstancial: ser salvada. Julián Marías comenta: “Y como toda persona humana está afectada por esa misma insuficiencia y menesterosidad, aquí encontramos la razón de que el ser personal, pensado hasta sus últimas consecuencias, remita a la necesidad de eso que se designa con una palabra oscura si las hay: salvación" (Antropología 38). Hay que ascender en el entendimiento del hombre, la fenomenología no puede ser tenida en cuenta sólo con la necesidad de conocer la 
relación del hombre con las cosas. Marías propone el camino que va de las cosas a la persona, de la persona como yo a los otros; sólo en esta medida hablar de la realidad puede resultar más esclarecedor ya que ésta no es impersonal. Él mismo dirá: “¿De la realidad? podría preguntarse $¿$ De toda realidad? En cierto sentido, sí, aunque esto pueda parecer extraño. Porque no tiene ningún sentido hablar de realidad sin referencia a mí" (Antropología 39).

Ortega y Gasset está convencido de que, a partir de su siglo, el tema que ocupará al ser humano de su tiempo será la política:

Creo muy seriamente que uno de los cambios más hondos del siglo actual con respecto al XIX va a consistir en la mutación de nuestra sensibilidad para las circunstancias. Yo no sé qué inquietud y con qué apresuramiento reinaba en la pasada centuria - en su segunda mitad sobre todo que impelía los ánimos a desatender todo lo inmediato y momentáneo de la vida (754).

Sorprende el perspectivismo orteguiano, sorprende la apuesta vital que hace junto a él Laín y Marías; el cuerpo no es sólo adaptable al medio que lo rodea, el medio también debe ser adaptable al cuerpo, propone Ortega y Gasset:

Este sector de realidad circunstante forma la otra mitad de mi persona: sólo a través de él puedo integrarme y ser plenamente yo mismo. La ciencia biológica más reciente estudia el organismo vivo como una unidad compuesta del cuerpo y su medio particular: de modo que el proceso vital no consiste sólo en una adaptación del medio a su cuerpo, sino también en la adaptación del cuerpo a su medio (756-767).

Todo esto permite esclarecer la necesidad de encarnar el espíritu o trascender el cuerpo asumiendo el compromiso personal que, como ser humano, se tiene con el acontecer histórico; comprendiendo que la historia no sólo se estudia, sino que, ante todo, se crea: “. .. la Historia es en tentativa, duda y osadía, inseguridad y responsabilidad. Por tanto, el hombre es un ser histórico porque además de finito es consciente, conoce su propia limitación" (Soler Puigoriol 126) y la asume para salvarse con ella. 
La manera cómo es asumido el cuerpo es lamentable, se llena de temores, se cortan sus alas, se vendan sus ojos, es obligado a no soñar; afirmar yo y cuerpo es no hacer del ser humano una "pasión inútil" sino intentar la superación de su imperfección presente, buscando un nuevo modo de ser humano que ponga en equilibrio estable la realidad vivida y la infinitud deseada (Soler Puigoriol 127).

\title{
Decir yo en la filosofía
}

La historia del yo en la filosofía es lo bastante amplia como para abarcarla en un corto tratado, por eso el camino que ahora se emprende es, ante la inmensidad de la historia, más breve. Conviene no reducir la experiencia del yo a un solo pensamiento, es mejor permitir que ella surja de los diversos aportes que los pensadores contemporáneos han dado para nuestro tiempo. Pero como no podría ampliarse a diferentes lugares y pensadores, por eso, al elegir para esta reflexión el pensamiento de Pedro Laín Entralgo, sería pertinente, antes de adentrarse un poco en su antropología del cuerpo, hacer una mención de la concepción filosófica que se tiene sobre el " yo" en el planteamiento español. No se puede, mucho menos, caer en una reducción antropológica. "Ciertamente, cuando digo yo, tú o un nombre propio, pienso en un cuerpo; conviene no olvidar esto en ningún momento, y no contentarnos con decir una vez y luego dejarlo inoperante al seguir pensando" (Marías, Antropología 35). Decir yo es el modo consciente como el cuerpo de cada ser humano se manifiesta, tal como dirá Laín:

\begin{abstract}
En este momento, miro y siento mi cuerpo, ¿Cómo lo percibo? ¿Qué es mi cuerpo para mí, cuál es el total significado del pronombre posesivo mi cuando lo refiero a mi cuerpo? ¿Qué dice mi cuerpo, acerca de mi viviente realidad, de la realidad que con muy diversas intenciones, tímidamente unas veces, retadoramente otras, de modo consciente o inconsciente actualizo cuando digo yo (Laín, Ser 305).
\end{abstract}

Conciencia del cuerpo, eso debe entender toda persona al mencionar el yo. Para que esto se posibilite es necesario que cada ser humano lea las situaciones que vive su cuerpo, experiencie su cuerpo, lo viva desde dentro y fuera. Siendo así, parecería fácil la labor, no lo es; Laín mismo califica la expresión del cuerpo de callado mensaje: "Analizando metódicamente la estructura de su callado mensaje, mi cuerpo me 
ofrece noticias elementales y originarias acerca de las siguientes notas de mi realidad: mi existencia, mi situación, mi capacidad para poder, $\mathrm{mi}$ capacidad para poseer" (Ser 305). Dicho de otra manera, en palabras de Pedro Soler Puigoriol, "[...] el yo es el sujeto de todas las acciones que realiza mi cuerpo; así, digo yo ando o yo siento dolor. Lo cual me indica que lo que mi cuerpo hace o siente está enraizado en mi yo" (54).

Miguel Ángel Villamil, al igual que Laín, señala la dificultad que tiene cada ser humano al experimentar su cuerpo, nos dice: "No obstante, también experimento situaciones donde mi cuerpo deja de ser el protagonista y se convierte en una especie de 'espectador pasivo'. Observo que cuando reflexiono y juzgo mis experiencias corpóreas, experimento la trascendencia de mi cuerpo: los actos no entrañan la totalidad de mi ser" (33). En palabras de Julián Marías Aguilera, no todas las partes del cuerpo pueden estar presentes a la hora de reconocerlo, dice: "La espalda no se puede ver, algunos puntos de la superficie del cuerpo no se pueden tocar" (Antropología 109). Si esto es así, queda preguntarnos ¿Cómo acceder al cuerpo de manera total? Marías tendrá la respuesta. Partirá del hecho de que no es la percepción el único camino que posibilita al ser humano tener conciencia de sí: "Si el hombre fuera sólo un animal perceptivo, o percipiente, su vida sería imposible, quiero decir no sería vida humana, no sería vida en el sentido que damos a esta expresión cuando hablamos de la nuestra. Y el hombre no sería persona" (Antropología 40).

El problema habita en la concepción que construyeron los modernos de conciencia; por eso, tanto Ortega y Gasset como Marías, denuncian la cosificación del yo en la modernidad, se dice: “El fenómeno primario es, pues, yo con la cosa; en términos más generales y más justos, yo con la realidad; y como, aunque esa realidad pueda ser cosa, en todo caso yo no lo soy, esa realidad primaria y total (yo con la realidad) no es cosa ni reductible al modo de ser de las cosas" (Marías, Antropología 40).

Para que la conciencia del cuerpo no quede bajo una mirada reduccionista, Marías propone el concepto de experiencia: “Experiencia es viajar, andar sin caminos, buscando los pasos, por eso Ortega ha podido decir, medio en broma, que la experiencia es "pensar con los pies". Si avanzamos, de las experiencias en sus formas parciales, a su manera radical, nos encontramos al lado de las experiencias de las cosas, la experiencia de la vida" (Antropología 41). 
Sobresale en su propuesta la aclaración del nuevo viaje que emprende la contemporaneidad, el del camino de las cosas al camino de la vida; la noción de cuerpo que se recorre en la actualidad es integral porque no queda reducida al estatuto de cosa, "se han introducido una vez y otra en la filosofía nuevas expresiones: yo, sujeto, conciencia, existencia, Dasein, subjetividad, pour-soi" (Marías, Antropología 46). Para el propio Ortega y Gasset la experiencia del yo no puede ser abordada como una cosa. "Usar, utilizar sólo podemos las cosas [...] Ahora bien: ante todo podemos situarnos en actitud utilitaria, salvo ante una sola cosa, ante una única cosa: Yo" (Ortega y Gasset 667). Todo esto con una finalidad: que el ser humano actual asuma con conciencia la realidad de su vida. Dice Marías:

\begin{abstract}
Mi vida acontece fuera de mí; si se prefiere, es un dentro que se hace un fuera. Por esto es acontecimiento o drama. La circunstancia - cuyo análisis minucioso ha sido hecho en otras ocasiones por Ortega y por mí - no es un conjunto de cosas, sino un escenario o mundo en que ese drama acontece, el yo no es cosa alguna, sino proyecto o programa, y esa circunstancia lo es porque es mía. Yo, como plena realidad, ejecutivamente, lejos de reducirme a ninguna subjetividad, co-implico o "complico" toda otra realidad que encuentro en cualquier forma, y consisto en ejercer una pasión anticipadora y futuriza sobre esa circunstancia (Antropología 48).
\end{abstract}

Pedro Soler Puigoriol ve este mismo camino atravesado por el concepto de libertad. Si la persona humana es libre elección, entonces hace de su cuerpo y del mundo circundante sus compañeros inseparables de viaje (53), comenta: "Nuestra libertad siempre la concebimos como facultad de elegir, y esta elección no la podemos entender como instalada en el vacío, sino en compañía de otros seres. El cuerpo, aunque pertenezca a nuestra esencia, es también el comienzo de lo ajeno; en nuestro ser, pero es también un poco lo otro" (53).

Culmina diciendo algo que nos interesa y que, aunque nos desinstale de la finalidad con que se viene escribiendo, es necesario tener presente: "Por eso cuando queremos estudiar al ser humano no podemos prescindir de su realidad corpórea; la vida del hombre es libertad, capacidad de entender y de amar; pero es también actividad de los órganos de percepción y función digestiva" (53). 


\title{
Del yo a los otros yo
}

El camino del yo no sólo está dirigido hacia la experiencia personal del cuerpo (mi cuerpo) y las circunstancias, también está orientado hacia otros yo, propone Ortega y Gasset:

\begin{abstract}
Más a lo que parece, nos es dado elegir ante otro hombre, ante otro sujeto, entre tratarlo como cosa, utilizarlo o tratarlo como Yo. Hay aquí un margen para el arbitrio, margen que no sería posible si los demás individuos humanos fueran realmente Yo. El tú, el él, son, pues, ficticiamente yo. En términos kantianos diríamos que mi buena voluntad hace de ti y de él como otros yo (667).
\end{abstract}

El yo no es un ser solitario que vive para sus propios fines, frente a sí tiene otros yo que le impiden arraigarse en su experiencia personal. Sólo cuando la experiencia del yo es auténtica, se descubre que el primer paso para abrirse a los otros es abrirse a sí mismo. Aun así, muchos hombres quedan oscurecidos por la experiencia de un yo solitario, se dejan envolver por la soledad y hacen de ella un estilo de vida, una idea para decir la filosofía. Marías lo expresa bellamente: "Si aíslo un cuerpo humano del resto del mundo, si lo dejo reducido a él mismo, muere por falta de alimento; si ese aislamiento es riguroso, todavía antes, por falta de respiración; es decir, la realidad efectiva del cuerpo viviente no termina en los límites de su piel, sino que envuelve el mundo en torno" (Antropología 105).

A esta experiencia que vive el ser humano dentro de su cuerpo se le ha dado el nombre de intercorporeidad. Según Villamil es necesario que el ser humano descubra su cuerpo para reconocer el del otro:

La intersubjetividad, en tanto intercorporeidad, es una situación que goza de evidencia plena. Siendo cuerpo, percibimos seres que no podemos instrumentalizar ni animalizar, porque distinguimos de inmediato que son cuerpos expresivos; es decir, otras fuentes de sentido, de significado, otros comportamientos y estructuras semejantes a la propia, con los cuales compartimos el mismo mundo (50). 


\section{Más allá de las ideas, una instalación del ser humano en su realidad radical}

Para el ser humano situarse es una actividad común, "en tanto que cuerpo cósmico, también el cuerpo del hombre realiza esa forzosidad ontológica de la situación; está en determinado lugar, en pie o sentado" (Laín, Ser 309). Situarse, actividad que realizamos como cuerpo, mejor expresada en el uso de un verbo: estar. Afirma Laín: "Pertenece a mi existencia la ineludible, constitutiva necesidad de estar en situación o, más directamente y sencillamente, de estar" (Ser 309).

Julián Marías fundamentará en su Antropología metafísica la importancia del verbo estar en la vida del ser humano, lo califica de "precioso e insustituible para comprender la vida humana" (Antropología 72). El verbo ser ha sido el utilizado para explicar la vida, pero "[...] estorba un poco para entender la vida humana; es, a lo sumo, un verbo secundario, apto para comprender ciertas determinaciones derivadas y consecutivas de la realidad primaria que es "vivir" (Antropología 72). El punto de referencia desde el cual Marías califica como adecuado el verbo estar en vez del verbo ser, está dado por la concepción proyectual que tiene de ser humano: "La vida es una operación que se hace hacia adelante. Yo soy, lo hemos visto antes, futurizo: orientado hacia el futuro, proyectado hacia él" (Antropología 72). Marías está convencido de que la realidad de ser humano es creación propia, en cuanto instalado el ser humano tiene la posibilidad de elegir quién quiere ser (Araujo 20).

Ortega y Gasset, Laín y Marías, ofrecen a la filosofía un nuevo camino para abordar al ser humano: ¿Quién es? Nos acerca a esta cuestión Ana María Araújo al interpretar: "Pero Marías no se queda allí. Inquieto por el quién del hombre busca su fundamento como persona, considera que la filosofía ya ha estudiado por muchos siglos el problema de la esencia y ahora debe enfrentar a la persona concreta, su actividad, su modo de ser, su fundamento, su historicidad" (19).

El estudio que Araújo ha realizado sobre Julián Marías permite hacer una mejor comprensión del proyecto por él elaborado; con éste, no sólo se hace referencia a un autor, también a su escuela de pensamiento. Según Araújo, la filosofía en Marías es concebida como un quehacer de la vida humana: "La vida no está hecha; al contrario tenemos que hacerla, y ella es lo que 
yo hago, el hacer mismo" (Marías, El tema 22). El compromiso vital de la persona acontece cuando ésta se decide a crear su propia empresa, de allí que se rescate el aspecto biográfico por medio del cual el ser humano se da cuenta que sólo éste, nadie más, necesita de un hacer (Araujo 31).

Sostener una relación con las cosas no es el único esfuerzo, también se debe sostener una relación permanente con la vida, afirma Marías:

\begin{abstract}
La vida consiste en una relación esencial del yo con las cosas; una relación, además constitutiva, porque el yo sólo se da o se constituye como tal cuando está con las cosas; la comprensión del ente humano, por tanto, las envuelve; no basta pues con el yo; ni siquiera con el yo y su soporte orgánico, es decir; lo que se llama el cuerpo y el alma; el hombre sólo se da en el mundo, y esta mundanidad o, si se quiere intramundanidad, lo constituye. En otros términos, la vida humana es una realidad peculiar que envuelve ontológicamente el ser de mi yo y el del mundo; y estos elementos, a su vez, sólo son abstracciones, y sólo alcanzan su ser verdadero en la totalidad de esa vida (El tema 21).
\end{abstract}

La vida es el lugar, el centro, la misión o, según Marías, la realidad radical de todo ser humano. En la medida que el ser humano vive, está, se instala y proyecta su vida, afirma para sí su compromiso personal, no hay que dar muchos rodeos para decir lo humano de otra manera, afirmarse como cuerpo ya es abrirse a la vida. Esto encuentra punto de comparación en lo expresado por Laín: “De ahí que las expresiones verbales en presente indicativo yo soy, yo pienso, yo ando sean en rigor fórmulas abreviadas de expresiones en gerundio: yo estoy siendo, yo estoy pensando, yo estoy andando. Por esencia, el hombre es un ente gerundial" (Ser 307).

\title{
A modo de conclusión
}

La filosofía en España logra desentrañar desde la antropología un camino de salida a su situación vital, ¡qué admirable!, ¿cuándo iniciamos nosotros? No tiene razón de ser que disfrutemos sus pensamientos sin encarnar nuestro espíritu en el aquí y ahora. Abordar sus obras debe arrebatar nuestra tranquilidad: ¿qué idea de ser humano poseemos en Latinoamérica? ¿hacia dónde encaminar nuestros esfuerzos? Definitivamente no hemos asumido de forma general nuestra deuda; pasado, presente y futuro siguen perdidos para 
nosotros. Tal vez escuchando consejos encontremos un punto desde dónde empezar, tanto Ortega y Gasset, como Zubiri, Laín y Marías, decidieron apartarse del pensamiento tradicional para comenzar un nuevo camino que posibilitó una experiencia propia del ser humano. Esto mismo descubre Pedro Soler Puigoriol en su estudio antropológico acerca de Laín, dice:

La empresa de ser hombre necesita soledad. En ella, separado del tiempo y de las cosas, toma conciencia de sí mismo y aquilata el valor de su existencia. Entonces se levanta parcialmente sobre el nivel del mundo y de la historia que le arrastran y vive su libertad. Liberado de las cosas, puede planear con originalidad los proyectos que van a dirigir su vida, los planos que le guiarán en su difícil empresa (45).

No podemos ser negativos frente a nuestra situación, el mismo Ortega y Gasset expresaba:

Hay, en cambio, un lugar, nada menos que un continente, donde el problema del hombre futuro, de la nueva cultura, es perentorio, y de la región sutil de la teoría desciende a cuestión política, casi palpable. Me refiero a América, esa Europa mejor a que aspiramos no puede ser, por lo pronto, sino en América, la viceversa es también verdad: América no puede ser sino una Europa mejor (470).

Muchos pensarán al leer a Ortega y Gasset que se refiere a la América del Norte, la del sueño del progreso, no es así: "Más América, muy especialmente Centro y Sud - América, es para nuestra vieja y melancólica sensibilidad metropolitana un enérgico canto de vida y de esperanza, como canta Rubén Darío, el indio divino. Tú eres mi mejor yo [...] ¡Argentina! ¡De los Andes al Atlántico, una inmensa matriz en que se concibe el hombre nuevo!" (470).

Hay que iniciar, la vida no se puede ir tras ideas y creencias, hay que actuar, vivir, proyectarse, hay una misión ¿Qué aconteció con la concepción de ese nuevo ser humano entre nosotros? Dar respuesta a este tipo de interrogantes debe ser la labor del intelectual, del pensador contemporáneo. Lastimosamente estamos aún inmersos bajo el encanto de lo otro, hemos banalizado lo nuestro fijando la mirada hacia el norte y el occidente; pensar(nos) es una actividad que debe 
sobrepasar el mero lenguaje, debe encarnarse en la realidad radical y en la (mi) realidad de cada persona. Es hora de asumir(se), de apropiarse de una antropología integral en la que el cuerpo tenga lugar, sea un proyecto de humanización, tal vez así, con-vivamos, co-ejecutemos y construyamos un proyecto de ser que supere el solipsismo moderno y encamine al yo a la constitución de una realidad comunitaria, a la nostridad, como le ha demoninado Laín Entralgo.

\section{REFERENCIAS}

Aguilar, Luis "La Corporalidad, del Desprecio al Respeto". Analogía Filosófica, 26, 2, 2012, pp. 151-173.

Araujo, Ana María. El pensamiento antropológico de Julián Marías. Editorial Universidad de la Sabana, 1992.

Buber, Martín. ¿Qué es el hombre? Trad. Eugenio Ímaz. Fondo de Cultura Económica, 1964.

Escobar, Jaime. Dimensiones Ontológicas del Cuerpo. Una visión filosófica del cuerpo humano y su relación con el ejercicio de la medicina. (2da. Ed.). Colección BIOS y ETHOS, 1998.

Husserl, Edmund. Ideas relativas a una fenomenología pura y una filosofía fenomenológica. (Trad. José Gaos). Fondo de Cultura Económica., 1949.

---. La crisis de las ciencias como una experiencia de la radical crisis vital de la humanidad europea. La Crisis de las ciencias Europeas y la fenomenología trascendental. Folios Ediciones, 1984.

Landmann, Michel. Antropología filosófica. (Trad. Carlos Moreno). UTEHA, 1961.

Laín Entralgo, Pedro. Antropología médica para clínicos. Salvat, 1986.

Laín Entralgo, Pedro. Idea del hombre. Galaxia Gutenberg, 1996.

Laín Entralgo, Pedro. Ser y conducta. Galaxia Gutenberg, 1996. 
Laín Entralgo, Pedro. Las Generaciones en la Historia. Diana, 1945.

Lyupen, William. Fenomenología existencial. (Trad. Pedro Martín y Carlos Lohlé). Ediciones Carlos Lohlé, 1967.

Marías Aguilera, Julián. Antropología Metafísica. Ensayos. Tomo X. Revista de Occidente, 1982.

---. El tema del hombre. Alianza Editorial. 1973.

Merlau-Ponty, Maurice. Fenomenología de la percepción. (Trad. Jem Cabanes). Península, 1975.

Ortega y Gasset, José. Obras Completas Tomo I (1902-1915). Taurus, 2004.

Rigobello, Armando. El porqué de la filosofía. Editorial Caparrós, 2000.

Sartre, Jean-Paul. El ser y la nada: ensayo de ontología fenomenológica. (Trad. Juan Valmar). Altaya, 1993.

Soler Puigoriol, Pedro. El hombre ser indigente. El pensamiento antropológico de Pedro Laín Entralgo. Guadarrama, 1961.

Villamil Pineda, Miguel A. Fenomenología del cuerpo y su mirar. Universidad de Santo Tomás, 2013.

\section{Como citar:}

García Echeverri, Jonny Alexander, et al. “Pedro Laín Entralgo, una visión filosófica del cuerpo: Yo soy mi cuerpo". Discusiones filosóficas. Jul. 21 (37), 2020: 115-142. https://doi.org/10.17151/difil.2020.21.37.7 